\title{
University Procurement Officers' Use of Technology When Seeking Information
}

\author{
Dan Bouhnik \\ Jerusalem College of Technology, Jerusalem, Israel, and \\ Bar-Ilan University, Ramat-Gan, Israel \\ bouhnik@jct.ac.il
}

\author{
Yahel Giat \\ Jerusalem College of \\ Technology, Jerusalem, Israel \\ yahel@jct.ac.il
}

\author{
Issachar Zarruk \\ Bar-Ilan University, Ramat-Gan, \\ Israel
}

Issachar.zarruk@biu.ac.il

\begin{abstract}
The transition from printed to electronic sources of information has resulted in a profound change to the way procurement officers seek information. Furthermore, in the past decade there have been additional technological revolutions that are expected to further affect the procurement process. In this paper, we conduct a survey among forty nine university procurement officers in Israel to examine to what extent procurement officers have adapted to smartphones and tablets by testing how frequently officers use notebooks, smartphones, and tablets for work-related and leisure purposes. We find that while officers prefer electronic sources of information over printed sources of information, officers have not yet adapted to the later technological advances (i.e., smartphones and tablets). Notebooks are more frequently used than either smartphones or tablets for work-related and leisure purposes. One explanation behind this result is that officers are not skilled in using smartphone and tablets applications. This implies that training officers in the use of these devices may improve their performance.
\end{abstract}

Keywords: Public procurement, information seeking behavior, notebooks, smartphones, tablets, information sources.

\section{Introduction}

Technological advancements, globalization, and increased competitiveness have led to tremen-

Material published as part of this publication, either on-line or in print, is copyrighted by the Informing Science Institute. Permission to make digital or paper copy of part or all of these works for personal or classroom use is granted without fee provided that the copies are not made or distributed for profit or commercial advantage AND that copies 1) bear this notice in full and 2) give the full citation on the first page. It is permissible to abstract these works so long as credit is given. To copy in all other cases or to republish or to post on a server or to redistribute to lists requires specific permission and payment of a fee. Contact Publisher@InformingScience.org to request redistribution permission. dous progress in organizations in general and the science of procurement in particular (Picoto, Bélanger, \& Palmados-Reis, 2014). As a result, the contribution of procurement to the organizations is increasingly important to operations and any inefficiency in the procurement process is detrimental to organizations' viability and success. 
Internet-based and other electronic sources have long been established to form a critically important platform for the procurement process (Garrido-Samaniego, Gutiérrez-Arranz, \& San JoséCabezudo, 2010). However, with the considerable technological advancements of recent years, it is not clear to what extent procurement officers actually use these advancements and integrate them in their work process.

The transition from a printed-oriented workplace to an electronic-oriented workplace has taken place over more than two decades ago, and within this electronic environment, too, there have been many substantial changes that profoundly affect the workplace (Powell, Darvell, \& Gray, 2003). Such changes include the change from desktops to portable computers (i.e., notebooks and laptops), the introduction of smartphones, and the introduction of tablets. The change from desktops to laptops did not entail any change in the software used to perform tasks since generally the same software was used in both types of devices. However, this change did promise portability and therefore posed a dramatic change in the way work was done. The changes to smartphone and tablets, too, are dramatic as these are different devices altogether that require adapting to them and learning how to operate their hardware, and more importantly, their novel software and applications.

As there is a gap between the purchasing of a new technology and the actual use of this technology (Lanzolla \& Suarez, 2012), it is interesting to examine to what extent these improvements have been adapted into the workflow of the procurement officers. Knowing which devices procurement officers use and don't use may lead to improvements in the design of these tools to meet the procurement officers' needs.

With this goal in mind, this research examines whether procurement officers are adept in the use of notebooks, smartphones, and tablets and at what frequency officers use these tools for workrelated or leisure purposes. Additionally, we examine the frequency at which officers use printed and electronic sources for work-related or leisure purposes.

The findings of this paper should be of interest to the managers of procurement departments and to those who train the procurement officers as well as to suppliers who need to communicate efficiently and effectively with the procurement officers. Moreover, Wilson (2000) claims that the research of information seeking behavior is an important field of research. The results of this paper, therefore, contribute to the field of information seeking behavior as well as the field of procurement.

\section{Literature Review}

\section{E-procurement}

McLaren and Middleton (2009) define e-procurement as any computer-based systems that facilitate the procurement of goods or services. de-Boer, Harink, and Heijboer (2002) describe six forms of e-procurement: e-MRO (maintenance, repair and operations), web-based ERP (enterprise resource planning), e-sourcing, e-tendering, e-reverse auctioning, and e-informing.

Ageshin (2001) remarks that e-procurement is the "child of the internet age" (p. 48). The internet increases the efficiency of the supplier-purchaser relationship since it allows the procurement officer to find new sources, services, and technology. The accessibility of the internet and its open nature is an important advantage over other forms of networks since it requires very low setup and operational costs and can be inexpensively adapted to changing situations (Muffatto \& Payaro, 2004).

E-procurement technology allows automatic and continuous work. It strengthens and leverages the organization resources and enables the identification of new sources and opportunities. These 
concepts and technologies provide significant benefits to the organizations who integrate them into their organizational culture. These benefits include lower administrative costs, shorter procurement cycle, decreased inventory, lower prices, and the introduction of the organizations into technological and business partnerships (Davila, Gupta, \& Palmer, 2003) and allow suppliers to assess their suppliers according to certain criteria (Bouhnik, Giat, \& Zarook, 2016). These partnerships are extremely beneficial as they increase the flow of information between the supplier and purchaser using systems such as inter-organizational information systems that form an efficient marketplace (Dai \& Kauffman, 2000).

Manufacturers should form platforms in which these suppliers can access the manufacturers' production plans and designs, thus enabling suppliers to participate in their private business environment. In this way, each supplier can manage its "virtual" warehouse and plan its own production schedule in alignment to his clients (Muffatto \& Payaro, 2004).

Indeed, the use of the internet to manage the supply chain is widespread due to its benefits. Moreover, procurement officers use search engines, forums, blogs, and other online services and features to seek and assess suppliers (e.g., Garrido-Samaniego et al., 2010; Osmonbekov, Bello, \& Gilliland, 2002). Li, Kong, Pang, Shi, and Yu (2003) find that the internet provides abundant and accurate information in a very accessible manner.

A very popular and promising approach to using the internet as an accessible source of information is the crowdsourcing approach. Crowdsourcing is the process of obtaining needed services, ideas, or content using the support of large groups of people, mostly an online community. This is in contrary to the traditional use of suppliers or employees. In the internet age, when procurement officers use the internet to obtain information, it is almost always by means of crowdsourcing (Safire, 2009). The term crowdsourcing may relate to a different types of operations such as crowd financing (e.g., Kickstarter.com, GoFundMe.com) search for answers or solutions (e.g., answerbag.com, answers.yahoo.com), and social media (e.g., twitter.com, facebook.com). For example, Sheffi (2015) explains that social media is an excellent tool for learning about events as they unfold and can therefore give real-time information for the procurement officers about possible disruptions in supply as they happen.

In addition to the use of generic sources of information, the procurement officers also use specialized sources of information, depending on the organization's domain. Garrido-Samaniego et al. (2010) claim that the engineering department works alongside the procuring department during the procurement process. They find that especially during the initial stages of the procurement process, the engineers' involvement is comparable to that of the procurement officers since the engineers must deal with the assessment of equipment, supplies, and suppliers and must guarantee that they meet their needs satisfactorily. Fidel and Green (2004) find that both engineers and procurement officers need to set criteria according to which tasks are assessed, the assignment of personnel is made and the choices of business interactions and investments are determined. Further, engineers and procurement officers must both engage in the continuous audit and control of their activities, and their work and time constraints are similar.

Kwasitsu (2003) finds that the four most important sources to engineers are staff and colleagues within the organization ( $68.6 \%$ of the sample), the engineer's personal notes $(60 \%)$, reliance on memory (60\%), and internet (49\%). Additionally, libraries and databases and reliance on conferences as a source of information increases with the academic level of the engineer. On the other hand, reliance on memory decreases with the engineer's academic level.

Similarly, Fidel and Green (2004) find that email, inter-personal communication, and the internet are the major sources of information of engineers. Hertzum and Pejtersen (2000) report that the type of information sources that the engineers use depends on the type of information needed. They find that most of the information is obtained through inter-personal relationships, profes- 
sional literature, and internal reports. However, to prioritize operations when planning a new project, engineers use mostly their interpersonal sources.

Research reports conflicting evidence as to what factors affect engineers in their choice of information sources. Hertzum and Pejtersen (2000) find that the cost of the information source, and not its quality, has the most effect on the choice of the information source. In contrast, Fidel and Green (2004) find that the engineers choose the information sources that are most convenient to them, that is, sources requiring less effort to assemble and analyze due to their format, accessibility, organization and ease of use. Further, Fidel and Green (2004) claim that past experience with the source of information is an important factor, too. Finally, Kwasitsu (2003) reports that the factors that affect most engineers' choice of information sources are accessibility ( $83 \%$ of the sample), availability (83\%), and quality (69\%). Kwasitsu (2003) finds that past experience and the cost of the information source are of less importance.

\section{Public Procurement}

Our research also intersects with research about public procurement since it is conducted in the procurement offices of public universities. As public institutions, universities' goals are not purely monetary. Procurement decisions, therefore, consider and support these other non-monetary goals. See, for example, Thurston and Eckelman (2011) about how procurement decisions can improve greenhouse gas emissions in Yale University.

Another important difference between public procurement and private procurement is the level of rules and regulations involved. This is mostly due to the need of reducing corruption and controlling public spending (e.g., Neupane, Soar, Vaidya, \& Yong, 2012; Nurmandi \& Kim, 2015). For example, Balaeva and Yakovlev (2015) find that in Voronezh State University small-sized procurement contracts come with a 19.1 percent (of the contract value) price tag. In contrast, for large contracts the cost of purchase reduces to only 1.1 percent of the contract value. These results point to the strong effect government procurement regulation has on the procurement process and its costs.

Additionally, procurement in public institutions and governmental entities has an important role in achieving robust growth and development. See, for example, Preuss (2007) about public procurement in the United Kingdom. Therefore, the procurement officer must use a wider range of information sources as he is not limited to purely economic parameters, but instead must have a comprehensive strategic social approach to his operations.

\section{Smartphone and Tablet Uses}

Ever since the marketing of the first iPhone in mid-2007 and the first iPad in 2010, smartphones and tablets have dramatically changed and redefined many business functions. These technological tools have the potential to increase the amount and frequency of information that we consume. The added mobility further allows access to information in many more locations. Despite these advantages, researchers are in dispute with how workers perceive smartphones and tablets. While some workers fully understand the advantages and utilize them, others are skeptical or simply unaware of the possibilities (Elrod, Brookshire, Cudney, \& Flachsbart, 2011).

Even when companies invest in a new technology, it does not necessarily mean that it will actually use it (see, for example, Lanzolla \& Suarez, 2012). For example, Oulasvirta and Sumari (2007) examine how employees choose among the vast number of mobile devices available to them. They find that employees chose the one that provides them with the most comfort, highest transmission efficiency, easiest reading of content, and the best access to information during a typical workday. 
Dearman and Peirce (2008) examine the use of smartphones, regular computers, and mobile computers among academics and industrial workers. They find that smartphones increase productivity. The increase in productivity is achieved by the fact that smartphones allow passing tasks between workstations and devices so that at each step the tool fitting the task at hand is used. The cost of this increased productivity, however, is the need to manage and mobilize tasks among a number of devices.

Karlson, Meyers, Jacobs, Johns, and Kane (2009) show that given the smart devices, the distinction between the personal and the professional life is blurred. This is done willingly by employees as they stay connected to their email continuously. For people searching for information for their daily profession tasks, the smartphone becomes a computerized device that connects a number of devices and doesn't function as a standalone device. Further, the smartphone cannot fulfill all the tasks that laptops are capable of doing and therefore it functions mainly as a backup device. As for fulfillment of tasks, this study shows that in some cases the subjects completed their assignments on their mobile and in others they postpone completion of their tasks until their laptop is handy.

Thakur, Gormish, and Erol (2011) find that smartphones are used only for jotting down notes, capturing texts and functional information, photograph storage, video tapping and decreasing the use of printers and laptops.

Pitichat (2013) observes that smartphones can be addictive, mixing personal and professional life, and cause detachment. Employees who use smartphones are pressured to manage more than one device, and these devises are counterproductive in meetings and conferences.

Muller. Gove, and Webb (2012) examine the use of tablets in day to day life and in the work place. They find that the main use of tablets is checking emails, social networks, and occasional information seeking. They conclude that tablets are more useful for personal needs rather than professional needs. Furthermore, they find that most tablet activity is simultaneous to other activities such as listening to seminars or lectures, watching the computer screen, conversation.

Eddy (2012) reports a study that finds that tablet use increases efficiency and productivity in organizations and encourages cooperation among employees. The main uses of tablets are as a support tool for salesmen and sales representatives, a marketing tool, and as a replacement for online documents. According to Geyer and Felske (2011) the tablet facilitates communication with management and encourages feedback from employees, thus creating a sense of involvement for the employee. The tablet is also a problem solving tool, as the workers can discuss various subjects at real time without being dependent on a computer.

Elrod et al. (2011) find that about half the employees in the industry use smartphone and tablet applications in some way at the workplace. These devices are used for internet navigation, sending emails, registering daily operations, special applications, and paperwork reduction.

\section{Research Questions}

In this study we use the terms recent technologies and traditional technologies to describe computer technologies as follows. Traditional technologies include desktops and notebooks including software such as Microsoft office and internet browsing tools. Recent technologies include smartphones, tablets and applications for these devices.

The research questions of this paper are:

Q1: What is the level of proficiency of the procurement officers in traditional computer tools compared to their proficiency of use of recent technologies. 
Following Elrod et al. (2011) there is no clear evidence as to whether workers have acquired sufficient proficiency in the recent technological developments. Since procurement officers in public universities typically stay many years on the job (due to tenure) and are therefore relatively older (the average age of the participants is 45 years), we hypothesize that the officer will report that they are more comfortable using the traditional technology.

Q2: Are there differences in the procurement officers' frequency of use of the technological devices (laptop, tablet, smartphone)?

Within this question we examine for what purpose each of the technological devices used. Karlson et al. (2009) and Thakur et al. (2011) find that smartphones are not used extensively in the workplace. Similarly, Muller et al. (2012) find that tablets' use for seeking information is only incidental. Accordingly, we hypothesize that the officer uses the laptop more frequently than the other devices.

Q3. Do the procurement officers use printed information sources more or less frequently than electronical information sources?

Within this question we examine for what purpose are electronic and printed information sources used. Following the numerous papers who find that electronic sources are the major source of information of the procurement officers (e.g., Garrido-Samaniego et al., 2010; Muffatto and Payaro 2004; Osmonbekov et al., 2002) we hypothesize that electronical sources are the primary source of information of the procurement officers.

\section{Methodology}

\section{Research Procedure and Participants}

The higher education system in Israel comprises eight public universities and many more public and private colleges. Universities are considerably bigger than colleges, cover a wider range of fields of study and are more research oriented than the colleges. For this research, seventy nine procurement officers from each of the eight universities in Israel were sent an email with an invitation to complete the questionnaires online. Each participant was provided with a brief explanation of the research and instructions on how to complete the questionnaire.

Forty nine questionnaires were filled and these comprise the research population. The participants comprise twenty four male (49\%) and twenty five female (51\%). The academic education of the participants is $18.4 \%(\mathrm{~N}=9)$ have a Master's degree or higher, $57.1 \%(\mathrm{~N}=28)$ have a Bachelor's degree, $18.4 \%(\mathrm{~N}=9)$ have a vocational school certification and $6.1 \%(\mathrm{~N}=3)$ completed high school. The participants' ages range between 26 and 71 years $(M=45.41, S D=13.73)$. Seniority at their workplace ranges between 3 and 40 years $(M=13.21, S D=11.64)$. For each item the results are reported only from questionnaires that completed the item.

\section{Research Tools}

Participants were asked to complete two questionnaires:

1. Demographic questionnaire.

This questionnaire includes items about the gender, age, place of work, seniority at workplace and level of education. The results of this questionnaire are reported above.

2. Questionnaire examining the device and information sources preferences of procurement officers.

This questionnaire is attached as an appendix. 
The first item of the questionnaire asks about the officer's proficiency of the classical traditional computer software and applications. We use a scale of one (no proficiency) to five (very proficient). The reliability of this item (Cronbach's alpha) is $\alpha=0.700$.

The second item of the questionnaire asks about the officer's proficiency with recent technology and their applications. We use a scale of one (no proficiency) to five (very proficient). The reliability of this item is $\alpha=0.700$.

The third item examines the frequency of use of laptops for work-related or leisure purposes. We further divide the work related purposes to three specific procurement related activities and ask the officers to report the frequency of use for each of these activities. We use a scale of zero (never) to six (at least daily). The reliability of this item is $\alpha=0.637$.

The fourth and fifth items repeat the third item for smartphones and tablets, respectively. The reliability of these items are $\alpha=0.834$ and 0.925 , respectively.

The sixth and seventh items examine the frequency of use of printed information sources and electronic information sources, respectively. The participants are asked to report to what degree they use these sources for work-related and leisure purposes. We further divide the work-related purposes to three specific procurement-related activities and ask the officers to report the frequency of use for each of these activities. We use a scale of zero (never) to six (at least daily).

\section{Research Limitations}

The participants of this research are forty nine officers from universities in Israel. The small number of participants dictates that the results must be considered carefully before they are generalized to different procurement domains. Furthermore, public procurement depends heavily on the regulatory environment (e.g., Balaeva \& Yakovlev, 2015) and considers objectives broader than just monetary costs (e.g., Thurston \& Eckelman, 2011 and Preuss, 2007) and therefore one must be cautious about generalizing the results to other industries and countries.

\section{Results}

\section{Research Question 1}

To answer the first research question we report the results of the first two items of the questionnaire. In Table 1 we report the mean and standard deviation of the answers to the first two items.

Table 1: The mean and standard deviation of the proficiency in traditional and recent technologies $(\mathrm{N}=46)$

\begin{tabular}{|l|l|l|}
\hline The technology & M & SD \\
\hline Traditional Technologies & 4.10 & 0.71 \\
\hline Recent Technologies & 3.78 & 0.65 \\
\hline
\end{tabular}

The participants proficiency in traditional technologies $(\mathrm{M}=4.1, \mathrm{SD}=0.71)$ is higher than the proficiency in recent technologies $(M=3.78, S D=0.65)$. This result is significant $t(90)=2.25, \mathrm{p}<0.05$.

\section{Research Question 2}

To answer the second research question we report the results of items three, four and five. In Table 2 we report the average response to these items. 
Table 2: The mean and standard deviation of the frequency of use of devices

\begin{tabular}{|c|c|c|c|c|c|c|}
\hline \multirow{2}{*}{ The purpose } & \multicolumn{2}{|c|}{$\begin{array}{l}\text { Laptop } \\
(\mathrm{N}=46)\end{array}$} & \multicolumn{2}{|c|}{$\begin{array}{l}\text { Smartphone } \\
(\mathrm{N}=42)\end{array}$} & \multicolumn{2}{|c|}{$\begin{array}{l}\text { Tablet } \\
(\mathrm{N}=41)\end{array}$} \\
\hline & M & SD & $\mathrm{M}$ & SD & $\mathrm{M}$ & SD \\
\hline Work-related & 6.00 & 0.00 & 3.12 & 2.64 & 0.68 & 1.59 \\
\hline Leisure & 5.54 & 0.66 & 4.64 & 2.25 & 1.66 & 2.48 \\
\hline General procurement updates & 4.28 & 1.83 & 1.55 & 1.95 & 0.56 & 1.45 \\
\hline $\begin{array}{l}\text { Information about conferences and professional } \\
\text { meetings }\end{array}$ & 2.72 & 2.06 & 1.26 & 1.81 & 0.56 & 1.45 \\
\hline Information about suppliers & 4.61 & 1.74 & 1.33 & 1.88 & 0.54 & 1.36 \\
\hline
\end{tabular}

\section{Work-related or Leisure}

All the participants reported that they use their laptop for work-related purposes on a daily basis. The use of the laptop for leisure is also very high $(\mathrm{M}=5.54, \mathrm{SD}=0.66)$. Thus, the participants use their laptops more frequently for work-related purposes than for leisure. This result is significant $\mathrm{t}(90)=4.72, \mathrm{p}<0.001$.

In contrast to the laptop, the participants report using the new technologies more frequently for leisure than for work-related needs. Smartphones are used for work-related purposes $(\mathrm{M}=3.12$, $\mathrm{SD}=2.64)$ less than leisure $(\mathrm{M}=4.64, \mathrm{SD}=2.25)$. This result is significant $\mathrm{t}(82)=2.84, \mathrm{p}<0.01$. Tablets are used for work-related purposes $(\mathrm{M}=0.68, \mathrm{SD}=1.59)$ less than leisure $(\mathrm{M}=1.66$, $\mathrm{SD}=2.48)$. This result is significant $\mathrm{t}(80)=2.13, \mathrm{p}<0.05$.

\section{Differences between Devices}

For work-related purposes, the use of laptops is significantly higher than the use of smartphones and tablets, $(\mathrm{t}(86)=7.07, \mathrm{p}<0.001$ and $\mathrm{t}(85)=21.42, \mathrm{p}<0.001$, respectively). Smartphones are used significantly more than tablets $(\mathrm{t}(81)=5.11, \mathrm{p}<0.001)$.

These results are replicated also for leisure needs. That is, the use of laptops is significantly higher than the use of smartphones and tablets, $(\mathrm{t}(86)=2.50, \mathrm{p}<0.05$ and $\mathrm{t}(85)=9.7, \mathrm{p}<0.001$, respectively). Smartphones are used significantly more than tablets $(\mathrm{t}(81)=5.73, \mathrm{p}<0.001)$.

\section{Research Question 3}

To answer the third research question we report the results of items six and seven. In Table 3 we report the average response to these items. 
Table 3: The mean and standard deviation of the frequency of use of the information sources

\begin{tabular}{|l|c|c|c|c|}
\hline \multirow{2}{*}{ The purpose } & \multicolumn{2}{|c|}{$\begin{array}{c}\text { Printed Sources } \\
(\mathrm{N}=44)\end{array}$} & \multicolumn{2}{|c|}{$\begin{array}{c}\text { Electronic } \\
\text { Sources (N=44) }\end{array}$} \\
\cline { 2 - 5 } & $\mathrm{M}$ & $\mathrm{SD}$ & $\mathrm{M}$ & $\mathrm{SD}$ \\
\hline Work-related & 2.61 & 2.21 & 5.16 & 1.66 \\
\hline Leisure & 2.75 & 2.00 & 4.82 & 1.87 \\
\hline General procurement updates & 1.66 & 1.87 & 3.55 & 2.06 \\
\hline $\begin{array}{l}\text { Information about conferences and professional meet- } \\
\text { ings }\end{array}$ & 1.16 & 1.63 & 2.23 & 2.06 \\
\hline \begin{tabular}{l} 
Information about suppliers \\
\hline
\end{tabular} & 1.68 & 2.05 & 4.09 & 2.01 \\
\hline
\end{tabular}

Electronic sources are preferred to printed sources for work related purposes as well as leisure. These results are significant $(\mathrm{t}(86)=6.12, \mathrm{p}<0.001$ and $\mathrm{t}(86)=5.01, \mathrm{p}<0.001$, respectively).

\section{Discussion}

In this research, we examine the behavior of procurement officers seeking information about suppliers. Concerning the first research question we find that procurement officers are computerliterate, i.e., officers report that they use Microsoft Office Suite and/or other comparable computer software. However, they are slow to adapt to the recent technology developments and report that they are not very skilled in the use of tablets and smartphone applications.

This result may reflect the fact that the computer tools needed for the procurement serves all types of officers including those who are not technology-oriented. Indeed, the position of a procurement officer does not require a Bachelor degree and one quarter of the participants do not have such a degree. Furthermore, many of those who have graduated university, graduated in non-technological fields. This result reveals a degree of ignorance with regard to the use of smartphone and tablet applications. Officers opt for the familiarity of the computer instead of exerting the extra effort of learning new technologies.

The consequences of these findings to the organization may be dramatic. As Sheffi (2015) explains, social media is the most important tool for real-time detection of supply disruptions. To be so rapidly informed the officer must be continuously online, requiring constant use of smartphones or tablets. The cost, therefore, of the officers limiting their use of smartphones may be severe, if, it happens that they miss the opportunity to foresee supply disruptions.

The second research question examined whether there are differences in the frequency of use of the technological devices. We hypothesized that there will be differences and that officers use their laptop more frequently than smartphones and tablets. Moreover, smartphones were used more frequently than tablets. These results were found to be true for work related purposes and for leisure.

This finding reiterates the findings of the first research question. The added value of the smartphone and tablet is their mobility. Since, however, a procurement officer spends most of the workday in his office using a computer, these mobile devices are not critical to the officer's work. These findings support Oulasvirta and Sumari's (2007) claim that the smartphone is an important continuance tool for office tasks started on the office computer. Similarly, Karlson et al. (2009) 
state that the smartphone cannot fill all the tasks that may be carried out on the computer and therefore acts only as a backup tool. Our findings also support Muller et al. (2012) who find that tablets are used mostly as secondary to computers.

Despite the existence of advanced technological tools, the procurement officer prefers the computer screen and is less interested in the mobility of smartphones and tablets. It is, however, important for officers to understand that these mobile tools are a very useful technology that may work well in an organizational setup because people can carry it on them at all times (Pitichat, 2013). As Geyer and Felske (2011) point out, they can upgrade the idea of information transfer and improve organizational communication without computer dependence. Accordingly, officers should overcome their wariness and make the effort to integrate these tools in their work process.

Our findings that officers use their tablets and smartphone for leisure purposes more frequently than for work-related needs further supports Muller et al. (2012) who reach similar conclusions. Indeed, Thakur et al. (2011) also claim that smartphones are used only anecdotally at work and therefore it is reasonable to assume that these tools are used more for leisure-related needs.

Another possible explanation to the limited use of smartphones and tablets is rooted in the fact the universities in Israel are public entities. Similar to Neupane et al. (2012) and Nurmandi and Kim (2015) public institutions must follow strict regulations to prevent misuse of public funds and corruption. These regulations frequently require very specific online connections and use of software that are possible only on desktop computers, which reduces the advantages of the portable devices to the procurement officers.

The third research question examines whether the procurement officer uses printed sources more frequently than electronic sources. Our hypothesis that electronic sources are used more frequently than printed sources is validated. Indeed, similar to Wilson's (2000) argument, in the twenty first century, after widespread digital developments began and integrated itself into our lives in such a way that information consumers automatically turn to the internet and computerized sources, the use of printed information sources indeed declined in many areas. This tendency is evident from our research, as the procurement officers turn to the printed sources less than to the digitalized source although they have not completely abandoned the printed sources.

Indeed, as Davila et al. (2003) claim, online procurement technologies are integrated in companies and organizations and are setting a new standard with regard to acquisition of merchandise, planning future purchases, for sales and exchanges. These findings further support the research by Dai and Kauffman (2003) and Muffato and Payaro (2004) about the importance of virtual warehousing and digital acquisition to the procuring process.

\section{Conclusions}

In this paper, we empirically examine what technological tools and information sources procurement officers use as they seek information about suppliers and the procurement process.

We find that procurement officers have fully integrated electronic sources in their work environment and are using much less printed sources. This adaptation to the digital revolution does not mean that they are quick to adopt new technologies. In fact, the officers are wary of the new technologies of the recent decade (i.e., smartphones and tablets) and still prefer to use the more traditional electronic devices (i.e., laptops and computer software tools).

Since the daily use of smartphones and tablets is ever growing, we believe it is important to encourage officers to use these devices by developing more user-friendly applications and by assisting officers to improve their proficiency of these tools. The procurement profession requires an intimate knowledge of late technologies to provide the organization with the state of the art prod- 
ucts and services. Since smartphones and tablets are an integral part of the modern life it is expected that procurement officers will increase their use of these devices in the near future.

\section{Appendix - Questionnaire}

Each of the items 3-7 asks to fill an identical table. We provide this table only once for purposes of brevity.

1-2. What is your level of proficiency in the following tools:

\begin{tabular}{|l|l|l|l|l|l|}
\hline & 1 (none) & 2 & 3 & 4 & 5 (very much) \\
\hline 1. Traditional Technologies (e.g., MS Office) & & & & & \\
\hline $\begin{array}{c}\text { 2. Recent Technologies (e.g., tablets and } \\
\text { smartphones) }\end{array}$ & & & & & \\
\hline
\end{tabular}

3. How frequently do you use a laptop for the following purposes?

4. How frequently do you use a smartphone for the following purposes?

5. How frequently do you use a tablet for the following purposes?

6 . How frequently do you use printed sources for the following purposes?

7. How frequently do you use electronic sources for the following purposes?

$0=$ Never, $1=$ Rarely, 2=Monthly, 3=Bi-monthly, 4= Weekly, 5=Bi-weekly, 6=Daily.

\begin{tabular}{|l|l|l|l|l|l|l|l|}
\hline Purpose & 0 & 1 & 2 & 3 & 4 & 5 & 6 \\
\hline Work-related & & & & & & & \\
\hline Leisure & & & & & & & \\
\hline General procurement updates & & & & & & & \\
\hline $\begin{array}{l}\text { Information about conferences } \\
\text { and professional meetings }\end{array}$ & & & & & & & \\
\hline Information about suppliers & & & & & & & \\
\hline
\end{tabular}

\section{References}

Ageshin, E. A. (2001). E-procurement at work: A case study. Production and Inventory Management Journal, $42(1), 48$.

Balaeva, O., \& Yakovlev, A. A. (2015). Estimation of costs in the Russian public procurement system: A case study of Voronezh State University. Higher School of Economics Research Paper No. WP BRP 41.

Bouhnik, D., Giat, Y., \& Zarook, I. (2016). Supplier assessment, selection by university procurement officers. Working Paper, Jerusalem College of Technology.

Dai, Q., \& Kauffman, R. J. (2000). Business models for internet-based E-procurement systems and b2b electronic markets: An exploratory assessment. Paper submitted to the 34th international conference on Systems Science.

Davila, A., Gupta, M., \& Palmer, R. (2003). Moving procurement systems to the internet: The adoption and use of e-procurement technology models. European Management Journal, 21(1), 11-23. 
De Boer, L., Harink, J., \& Heijboer, G. (2002). A conceptual model for assessing the impact of electronic procurement. European Journal of Purchasing \& Supply Management, 8(1), 25-33.

Dearman, D., \& Pierce, J. (2008). "It's on my other computer': Computing with multiple devices. In Proceedings of CHI 2008, pp. 767-776. New York: ACM Press.

Eddy, N. (2012, May 16). Tablet, Smartphone Use Increasing Worker Productivity: CDW. eWeek. Retrieved November 25, 2015 from http://www.eweek.com/c/a/Mobile-and-Wireless/Tablet-SmartphoneUse-Increasing-Worker-Productivity-CDW-779688

Elrod, C. C., Brookshire, C., Cudney, E. A., \& Flachsbart, B. B. (2011). iPhone and iPad applications: Perceptions of use in an organization's supply chain. Issues in Information Systems, XII(1), 170-180.

Fidel, R., \& Green, M. (2004). The many faces of accessibility: Engineers' perception of information sources. Information Processing \& Management, 40(3), 563-581.

Garrido-Samaniego, M. J., Gutiérrez-Arranz, A. M., \& San José-Cabezudo, R. (2010). Assessing the impact of e-procurement on the structure of the buying centre. International Journal of Information Management, 30(2), 135-143.

Geyer, M., \& Felske, F. (2011). Consumer toy or corporate tool: The iPad enters the workplace. Interactions, 45-49.

Hertzum, M., \& Pejtersen, A. M. (2000). The information-seeking practices of engineers: Searching for documents as well as for people. Information Processing \& Management, 36(5), 761-778.

Karlson, A. K., Meyers, B. R., Jacobs, A., Johns, P., \& Kane, S. K. (2009). Working overtime: Patterns of smartphone and PC usage in the day of an Information worker. Lecture Notes in Computer Science, $5538,398-405$.

Kwasitsu, L. (2003). Information-seeking behavior of design, process, and manufacturing engineers. $L i$ brary \& Information Science Research, 25(4), 459-476.

Lanzolla, G., \& Suarez, F. F. (2012). Closing the technology adoption-use divide The role of contiguous user bandwagon. Journal of Management, 38(3), 836-859.

Li, H., Kong, C.W., Pang, Y.C., Shi, W.Z., \& Yu, L. (2003). Internet-based geographical information system for e-commerce Application in construction material procurement. Journal of Construction Engineering and Management, 689-697.

McLaren, T., \& Middleton, C. (2009). My how you've grown! eProcurement in the post-dot-bomb era. In Exploring the grand challenges for next generation e-business (pp. 298-309). Springer Berlin Heidelberg.

Muffatto, M., \& Payaro, A. (2004). Integration of web-based procurement and fulfillment: A comparison of case studies. International Journal of Information Management, 24, 295-311.

Muller, H., Gove, J. L., \& Webb, J. S. (2012). Understanding tablet use: A multi-method exploration. Proceedings of the 14th Conference on Human-Computer Interaction with Mobile Devices and Services (Mobile HCI 2012), ACM.

Neupane, A., Soar, J., Vaidya, K., \& Yong, J. (2012). Role of public e-procurement technology to reduce corruption in government procurement. In Proceedings of the 5th International Public Procurement Conference (IPPC5) (pp. 304-334). Public Procurement Research Center.

Nurmandi, A., \& Kim, S. (2015). Making e-procurement work in a decentralized procurement system: A comparison of three Indonesian cities. International Journal of Public Sector Management, 28(3), 198220.

Osmonbekov, T., Bello, D. C., \& Gilliland, D. I. (2002). Adoption of electronic commerce tools in business procurement: Enhanced buying center structure and processes. Journal of Business \& Industrial Marketing, 17(2/3), 151-166. 
Oulasvirta, A., \& Sumari, L. (2007). Mobile kits and laptop trays: Managing multiple devices in mobile information work. In Proceedings CHI 2007, 1127-1136. New York: ACM Press.

Picoto, W. N., Bélanger, F., \& Palma-dos-Reis, A. (2014). An organizational perspective on m-business: Usage factors and value determination. European Journal of Information Systems, 23(5), 571-592.

Pitichat, T. (2013). Smartphones in workplace: Changing organizational behavior, transforming the future, LUX. A Journal of Transdiciplinary Writing and Research from Claremont Graduate University, 3(1), $1-10$.

Powell, J. A., Darvell, M., \& Gray, J. A. M. (2003). The doctor, the patient and the world-wide web: How the internet is changing healthcare. Journal of the Royal Society of Medicine, 96(2), 74-76.

Preuss, L. (2007). Buying into our future: Sustainability initiatives in local government procurement. Business Strategy and the Environment, 16, 354-365.

Safire, W. (February 5, 2009). On Language. New York Times Magazine. Retrieved on July 15, 2014.

Sheffi, Y. (2015). Preparing for disruptions through early detection. MIT Sloan Management Review, 57(1), 31.

Thakur, A., Gormish, M., \& Erol, B. (2011). Mobile phones and information capture in the workplace. In CHI'11 Extended Abstracts on Human Factors in Computing Systems (pp. 1513-1518). ACM.

Thurston, M., \& Eckelman, M. J. (2011). Assessing greenhouse gas emissions from university purchases. International Journal of Sustainability in Higher Education, 12(3), 225-235.

Wilson, T. (2000). Human information behavior. Informing Science Journal, 3, 49-56. Retrieved from http://www.informingscience.org/Publications/576

\section{Biographies}

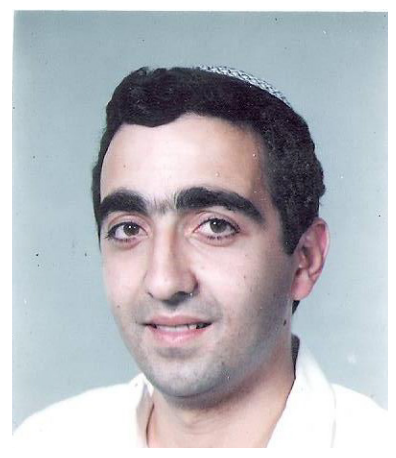

Dr. Dan Bouhnik is a faculty member in the Information Science department in Bar Ilan University (BIU) and in the Computer Science department in the Jerusalem College of Technology (JCT) in Israel. He is the author of a number of books used for teaching Advanced Computer Sciences and his professional interests include virtual learning and its effect on the thinking process, information needs of special groups as well as the infusion of new technologies in the learning environment.

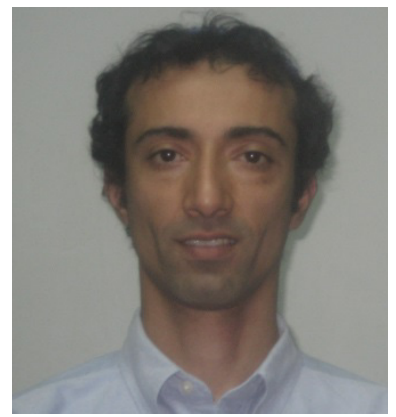

Dr. Yahel Giat is a tenured faculty member in the Department of Industrial Engineering and Management in the Jerusalem College of Technology. He holds a Ph.D. and an MSc. in Industrial Engineering from the Georgia Institute of Technology, an MSc. in Economics, a B.Sc. in Electrical Engineering and B.A. in Computer Sciences from the Israel Institute of Technology. 


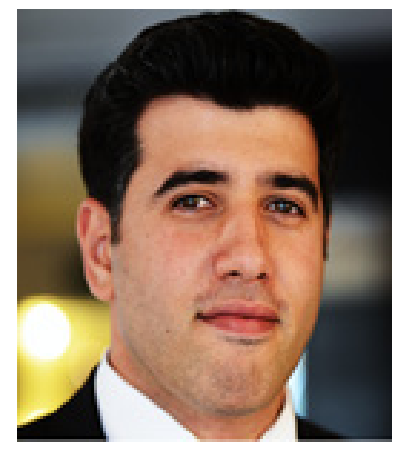

Mr. Issachar Zarruk is a Purchasing Manager at Bar-Ilan University (BIU) in Israel. He is pursuing a PhD in Information Sciences at BIU.

He holds a Master degree in Logistics Management from BIU and a BA in Economics and Business Management from Ariel University. 